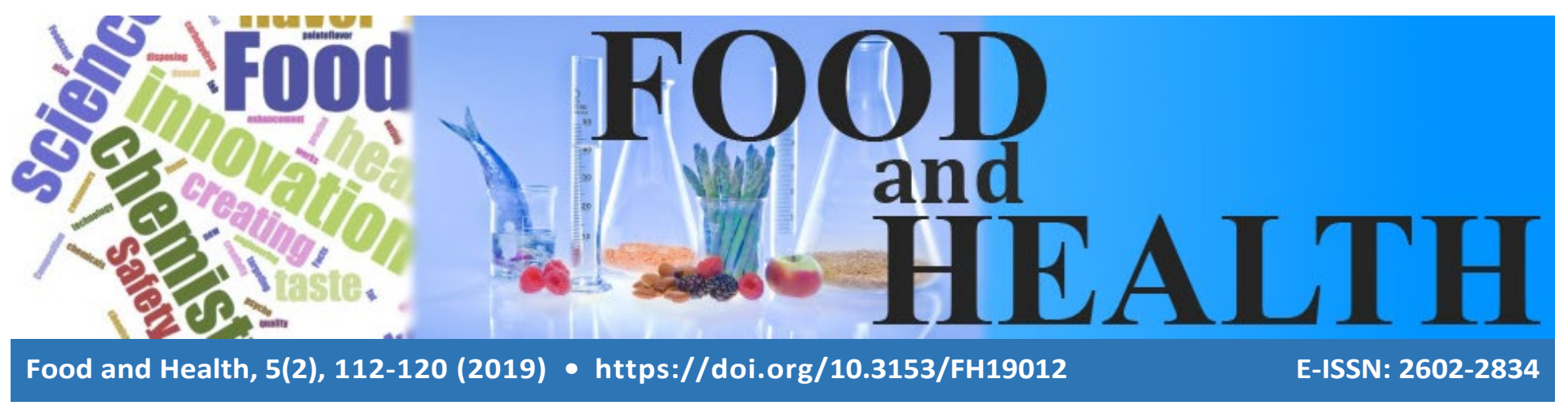

Research Article

\title{
DETERMINING THE LEVEL OF FOOD SAFETY AWARENESS AMONG FOOD PROFESSIONALS: A CASE STUDY OF TURKEY AND NIGERIA
}

\author{
Osman Çavuş $^{1}{ }^{\oplus}$, Balarabe Bilyaminu Ismail $^{2,3}$ (), Fügen Durlu Özkaya ${ }^{4}$ ()
}

Cite this article as:

Çavuş, O., Ismail, B.B., Özkaya Durlu, F. (2019). Determining the level of food safety awareness among food professionals: a case study of Turkey and Nigeria. Food and Health, 5(2), 112-120. https://doi.org/10.3153/FH19012

\footnotetext{
1 Department of Gastronomy and Culinary Arts, Abant İzzet Baysal University, Turkey

2 College of Biosystems Engineering and Food Science, Zhejiang University, Hangzhou 310058, China

Department of Food Science and Technology, Faculty of Agriculture, Bayero University, Kano. PMB 3011, Kano, Nigeria

${ }^{4}$ Department of Gastronomy and Culinary Arts, Ankara Hacı Bayram Veli University, Turkey
}

ORCID IDs of the authors: O.Ç. 0000-0002-9815-4424

B.B.I. 0000-0002-0153-4333

F.D.Ö. 0000-0003-2893-9557

Submitted: 17.05 .2018

Accepted: 14.10 .2018

Published online: 01.12 .2018

Correspondence:

Osman ÇAVUŞ

E-mail: osmancavus@ibu.edu.tr

๑) Copyright 2019 by ScientificWebJournals Available online at http://jfhs.scientificwebjournals.com

\begin{abstract}
In this study, 284 food professionals including chefs and students of food science-related courses were surveyed to determine their level of business regarding allergens in foods and food safety in general were determined through questionnaire survey. A questionnaire comprising of 19 questions covering specific food safety issues and allergens in foods were used to collect information for the study through face to face interviews. Interviews were conducted for 284 people in Nigeria and Turkey. One hundred and ninety-five (68.7\%) of the respondents were from Turkey whereas 89 $(31.3 \%)$ were from Nigeria. Out of the $68.7 \%$ respondents from Turkey; $68.7 \%$ were students and $31.3 \%$ were chefs. The $31.3 \%$ respondents from Nigeria were $33.7 \%$ students and $66.3 \%$ chefs. The result of the study indicated that the findings of scientific studies on food safety have not been directly applied by the people working in the food sector. Additionally, the knowledge level of the gastronomy and culinary arts students on food safety and allergens are higher than the restaurant chefs that prepare foods for the consumers. The restaurant as a significant part of the food chain industry must be well-prepared to face an increasing number of clients with food allergies.
\end{abstract}

Keywords: Allergens, Food safety, Consumer awareness, Questionnaire survey 


\section{Introduction}

The single most vital task of food scientists and the food industry as a whole is to ensure the safety of foods supplied to consumers. The recent trends in global food production, distribution and preparation necessitated the need for an increased emphasis on hygienic practices at all levels and for increased research in food safety in order to ensure a safer global food supply (Anna and Richard, 2007; Gong et al., 2016). Prokopov and Tanchev (2007) opined that it is specifically an important role of food scientists to make foods as safe as possible regardless of whether they are used fresh or being processed. The judicious utilization of application of food processing, storage, and preservation techniques will help to prevent foodborne illness outbreaks thereby ensuring adequate protection of the health of the consumers.

In this 21 st century that we are, food safety issues have had as high a priority and significance as they did over 100 years ago. There have been rising public concerns regarding highprofile food-borne illness outbreaks due to contamination of food with certain pathogens like Salmonella, Escherichia coli 0157:H7, Listeria monocytogenes, and others which have serious acute impact and potential chronic long-term complications especially in the ever-increasing high-risk population segment which include elderly, children and immuno-compromised (Ronald and Gary, 2002).

In addition to the foodborne related diseases, allergens in foods are also a growing food safety and public health concern globally and affect up to $2-8 \%$ of the world population and in the United States alone, $4 \%-6 \%$ of children are affected according to a report by the Centre for Disease Control and Prevention (CDC) of the United States. Further, allergic reactions happen when there is a specific and reproducible immune response by the human body systems that can be severe and life-threatening, particularly anaphylaxis. In people with food allergy, the immune system that supposedly protect them from germs will mistakenly respond to food as if it were harmful (Branum, et al., 2008; Zhang, et al., 2016). There are eight foods that are said to contain allergenic materials accounting for $90 \%$ of serious allergic reactions in the United States and Europe. These include; milk, eggs, fish, crustacean shellfish, wheat, soy, peanuts, and tree nuts (FSA, 2013). The allergen rules came into effect in the UK and the EU on 13 December 2014. According to this regulation, food businesses must emphasize the major allergens on the product label within the ingredients list (FSA, 2013).

Implementation of the studies in food safety, identified standards, legal regulations issued in this regard by the con- scious people is extremely important since they should provide solid outcomes for the public health (Hassan and Dimassi, 2014). In order to realize this aim, gastronomy, and food science departments were established in many universities in the world to train qualified personnel in the food sector (Santich, 2004; Aduriz, 2012). As obtained in other parts of the world, there exist regulations on food allergens in Nigeria and Turkey where this research will be undertaken. However, there is no evidence to suggest that consumers are made to understand the risks associated with allergens and whether these regulations are fully enforced and effective on food businesses particularly in Nigeria and this makes it difficult to have any data on allergen prevalence, incidences, and measures taken so far.

This study is therefore aimed at determining the awareness level of Chefs and Students of Food related areas on food safety in general and allergens, in particular, giving the recommendations on the way forward.

\section{Materials and Methods}

A questionnaire comprising of 19 questions covering many food safety issues and allergens in foods were used to collect information for the study through face to face interviews. Questions were developed using samples of questions being used by the Food Standards Agency of the United Kingdom for its annual and biannual surveys on consumer attitudes to foods and food safety and other food safety agencies in the World. The demographic information of the respondents was also collected to determine whether it influences their responses to questions.

About 284 respondents from the age of 18 years and above participated in the survey conducted in Kano state, Nigeria and Ankara city in Turkey. Responses were collected specifically from students in Gastronomy and Culinary Arts, Nutrition, Food Science, and Chefs. Questions were translated to the respondents in the local language where necessary for easy interpretation.

Study 1 Survey on the consumer level of awareness on food safety issues

Respondents were asked six questions regarding their level of concern and awareness regarding general food safety issues. These include 1) Whether food safety is a major issue of concern facing them today 2) Whether they are concerned about food safety at all. 3) Respondents level of concern on food safety issues such as amounts of fats and salt in foods, use of additives, use of pesticides and food poisoning. Respondents were also asked whether they were getting any information on food safety and through which ways and 
who should be held responsible for providing information on food safety. The survey items were measure as using scale [ 1 as Yes, 2 as No, Concerned (1), Neutral (2) and not concerned (3)].

Study Survey on respondents' knowledge about allergens in foods and food labeling

Respondents were asked nine questions here to determine their level of awareness and concerns about food allergens and food labeling. The aim was to understand if there is a connection between knowledge on food allergens on one hand and food labeling on the other. Questions asked include 1) whether the respondents have any food allergy. 2) The level of concerns about food allergens and the perspective from which food allergy is important. 3) Respondents ability to identify allergenic foods. 4) Whether respondents have ever come across allergen warning on food packaging. Respondents were also asked on the specific information they look at when buying packaged foods, how easy they are finding food labels to understand, how important is food label in their decision of which food to buy and if they understand the meaning of "use by date" found in some food labels.

\section{Statistical Analyses}

The gathered data was analyzed using The Statistical Package for Social Sciences for Windows (SPSS Inc., version 17.0 Chicago, IL, 2007). Cross-tabulation tests were performed to determine the respondents' awareness level and concerns about food safety issues and food allergens on a comparative basis between Turkey and Nigeria. Statistical significance of $p<0.05$ was used for all tests.

\section{Results and Discussion}

\section{Demographics}

Of the 284 respondents, $68.7 \%$ were from Turkey and $31.3 \%$ from Nigeria. The vast majority of respondents from Turkey were students $(68.7 \%)$ and $31.3 \%$ were chefs. On the other hand, the majority of respondents from Nigeria were chefs $(66.3 \%)$ and $31.3 \%$ were students. In total, $57.7 \%$ students and $42.3 \%$ of chefs participated in this research. The percentage of male (49.7\%) in Turkey was almost the same to female $(50.3 \%)$, despite the fact that their counterpart from Nigeria was $56.2 \%$ male and $43.8 \%$ of them were female. The demographic information will be discussed were it has an influence on the responses to questions.

The research question 1 from the food safety section asked today's top major concern. The result as shown in figure 1 indicated that the majority of respondents in both Turkey and Nigeria mentioned that their top major concern is terrorism. This result was expected because nowadays terrorism has increased rapidly in all over the world. On the other hand, the interesting results are that respondents from Turkey indicated that the second major problem is standards in education $(27.8 \%)$, and food safety issue becomes a third major problem $(27.8 \%)$. However, respondents from Nigeria mentioned the second major problem today is food safety issues (31. 5\%). According to research, FSA and WHO indicate that cases of foodborne related diseases are growing every day in all over the world, for example in 2010, 582 million incidents and 351,000 deaths associated with 22 different foodborne diseases have been reported (Chapman et al., 2016). That is why it was expected from respondents (chefs \& culinary students) that at least food safety issues become a second major problem today.

Study 2 Survey on respondents' knowledge about allergens in foods and food labeling.

Respondents were asked to identify food allergens from the listed items. These are approved list of allergens as identified in the EU food standards. Hattersley et al., (2014) mentioned that allergenic foods are a major concern all over the world and all food handlers must know how to handle them. The result as presented in Table 1 indicated that $16.7 \%$ of chefs do not know anything about food allergens. This is very dangerous because they deal with food on daily basis and they serve people with these foods. Chefs must be able to understand allergens in foods and guide consumers to avoid negative effects of allergens. Furthermore, significant number of allergic reactions happens in the restaurants resulting from cross contamination, miscommunication between the waiters and cooks and undeclared ingredients (Lee \& Xu, 2015; Pratten \& Towers, 2004). It is interesting to know that only a few percentages of students $(8.5 \%)$ in food science, gastronomy, and culinary arts are not aware of food allergens. They are given the needed knowledge on food allergens. Kabacik (2013) in his study to Determine the Food Safety Knowledge Level of the Kitchen Staff Working For 4 And 5 Star Hotel Kitchens reported that students' knowledge level on food safety is significantly higher than that of the chefs.

Further, there is a significant difference between the respondents from Nigeria and that of Turkey with respect to their knowledge on food allergens. As indicated in Table 2, a quarter of the respondents from Nigeria (28\%) mentioned that they do not know allergenic foods but a majority (51.7\%) claimed they have allergy while only fewer percentage $(20 \%)$ of them correctly identify allergens from the list. In Turkey, on the other hand, the vast majority (70.8\%) 
of the respondents correctly identify allergens from the list with just a few (4.6\%) who mentioned that they don't know anything about allergenic foods. Additionally, fewer percentage $(3.1 \%)$ of the respondents indicated that they have an allergy. A graphical presentation of this distribution is presented in Figure 2.

\section{Importance of food allergen from different points of view}

Respondents were asked about the importance of food allergens from different points of view. The result in Table 3, indicated that the vast majority of the respondents in both countries are concerned about food allergens from a health point of view. Allergens in foods can cause a health risk to the consumers who are allergic to its components or ingredients added. It is to be noted that allergens can also be important from the food safety point of view meaning that the food will not cause any harm when prepared or consumed based on its intended use. Surprisingly, just a few percentages of the respondents were able to indicate that in their responses. Other authors have indicated a general lack of knowledge of food handlers on scientific information on food safety (Kunadu et al., 2016). These points clearly show that the scientific information and finding must be implemented by the food handlers otherwise foodborne related problems will continue. The study of Burke et al., (2016) indicated that food servers and producers have low knowledge of foodborne pathogens.

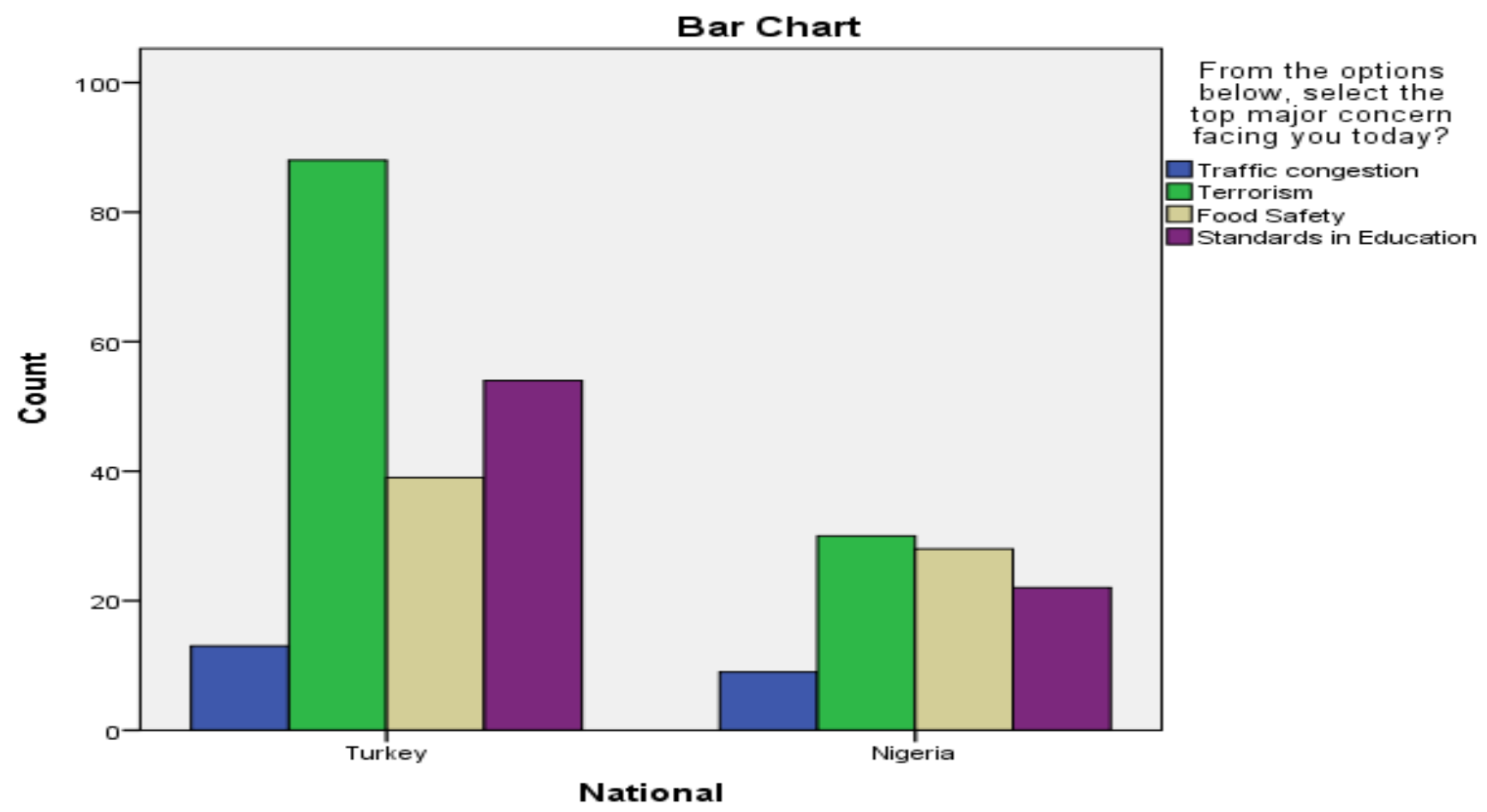

Figure 1. Major Concerns Facing Respondents Today 
Table 1. Knowledge amongst respondents about foods that contain allergens.

\begin{tabular}{|c|c|c|c|c|c|c|c|c|c|}
\hline \multicolumn{10}{|c|}{ Which of the following foods contains allergens? } \\
\hline & Wheat & Shell fish & Milk & Egg & Fish & Soy & $\begin{array}{l}\text { Peanuts and } \\
\text { its derivatives }\end{array}$ & $\begin{array}{l}\text { All of } \\
\text { them }\end{array}$ & $\begin{array}{l}\text { I don't know } \\
\text { anything about } \\
\text { allergic foods }\end{array}$ \\
\hline Chefs & $8.3 \%$ & $6.7 \%$ & $5.8 \%$ & $13.3 \%$ & $3.3 \%$ & $3.3 \%$ & $3.3 \%$ & $39.2 \%$ & $16.7 \%$ \\
\hline Students & $3.0 \%$ & $6.1 \%$ & $6.1 \%$ & $3.0 \%$ & $0.6 \%$ & $1.8 \%$ & $4.3 \%$ & $54.9 \%$ & $12.0 \%$ \\
\hline
\end{tabular}

Table 2. Which of the following foods contains allergens?

\begin{tabular}{|c|c|c|c|c|c|c|c|c|c|c|}
\hline \multicolumn{11}{|c|}{ Which of the following foods contains allergens (count within Nationalities)? } \\
\hline & & Wheat & Shell fish & Milk & Egg & Fish & Soy & $\begin{array}{l}\text { Peanuts and } \\
\text { its derivatives }\end{array}$ & $\begin{array}{l}\text { All of } \\
\text { them }\end{array}$ & $\begin{array}{l}\text { I don't know } \\
\text { anything about } \\
\text { allergic foods }\end{array}$ \\
\hline \multirow{2}{*}{ Nationalty } & Turkey & $3.6 \%$ & $7.7 \%$ & $1.0 \%$ & $6.2 \%$ & $1.5 \%$ & $1.0 \%$ & $3.6 \%$ & $70.8 \%$ & $4.6 \%$ \\
\hline & Nigeria & $9.0 \%$ & $3.4 \%$ & $16.9 \%$ & $10.1 \%$ & $2.2 \%$ & $5.6 \%$ & $4.5 \%$ & $20.2 \%$ & $28.1 \%$ \\
\hline
\end{tabular}

Table 3. The importance of allergenic foods from different points of view.

\begin{tabular}{ccccll}
\hline \multicolumn{6}{c}{ Allergens are important from which point of view? } \\
\hline & Food safety & Health point & Food quality & Not important at all \\
\hline \multirow{2}{*}{ Nationalty } & Turkey & $11.9 \%$ & $79.4 \%$ & $3.6 \%$ & $1.5 \%$ \\
\cline { 2 - 6 } & Nigeria & $23.6 \%$ & $57.3 \%$ & $4.5 \%$ & $13.5 \%$ \\
\hline
\end{tabular}

\section{Consumer Awareness on Food Labelling}

On food labelling, there is a significant difference between the respondents from Nigeria and that of Turkey with respect to 'how easy do you personally find foods label to understand'. The results were presented in Figure 3. The majority of the respondents from Nigeria (56.8\%) mentioned they understand food labels easily while a few percentages of them indicated that it is very hard to understand ( $8 \%)$. On the other hand, only $39.6 \%$ of the respondents from Turkey indicated that they understand food labels easily while a quarter of them $(25.6 \%)$ indicated that it is hard to understand. Accordingly, it looks like Nigeria's food labels are more understandable than their Turkish counterparts.

Respondents were asked about the information they look up when buying packaged foods. As shown in Figure 3, majority of the respondents in both Turkey (52.8\%) and Nigeria (51.1\%) lookup for all the mentioned information on the package. However, only a quarter (although the largest percentage) of the respondents in all the countries look up for best before/use by date despite its importance from the food safety point of view. Furthermore, despite the importance of nutritional information especially on allergens, very few of the respondents look for it when buying packaged foods. The 2007 survey conducted by the FSA in the UK on Consumer Attitudes to Food Standards revealed that respondents were more likely to look at the nutritional value and ingredient information than the "use by date". The change in attitude is likely to be attributed to the rising concern about food safety in recent years and the importance of the "use by date" as an indicator of food safety.

On the other hand, the results indicated only $40 \%$ of the chefs look at all the information on the food package. It is expected that the chefs should be more concerned about the information on the package especially in regards to their role in food preparation. However, 59\% of students mentioned that they look up all information on the package. This suggests a good understanding of the importance of food labels. A similar work was carried out by the Kunadu et al., (2016) indicated that food handlers never check the integrity of food package before use. Webb and Morancie (2016) also indicated food handlers do not have significant knowledge of food safety.

The respondents were asked if they ever come across allergen warning in the packaged foods or menu list at restaurants. The results show on Table 4, shows that, there is a 
significant difference between Nigerians and Turkish participants. The vast majority of Turkish respondents $(66.2 \%)$ indicated that they have not come across any warning in the packaged foods and menu at restaurants. The EU food regulation stipulated that major allergens must be emphasized on the product label (Smigic et al., 2016) and many restau- rants in Europe mention allergens alert in their menu. Answers from Nigeria's participants are so close (yes $32.6 \%$, no $34.8 \%$, I don't know $32.6 \%$ ) and if we look at those results, it clearly indicated that respondents from Nigeria are more concerned about this situation and that explains why respondents from Nigeria claimed to have more food allergy than their Turkish counterparts.

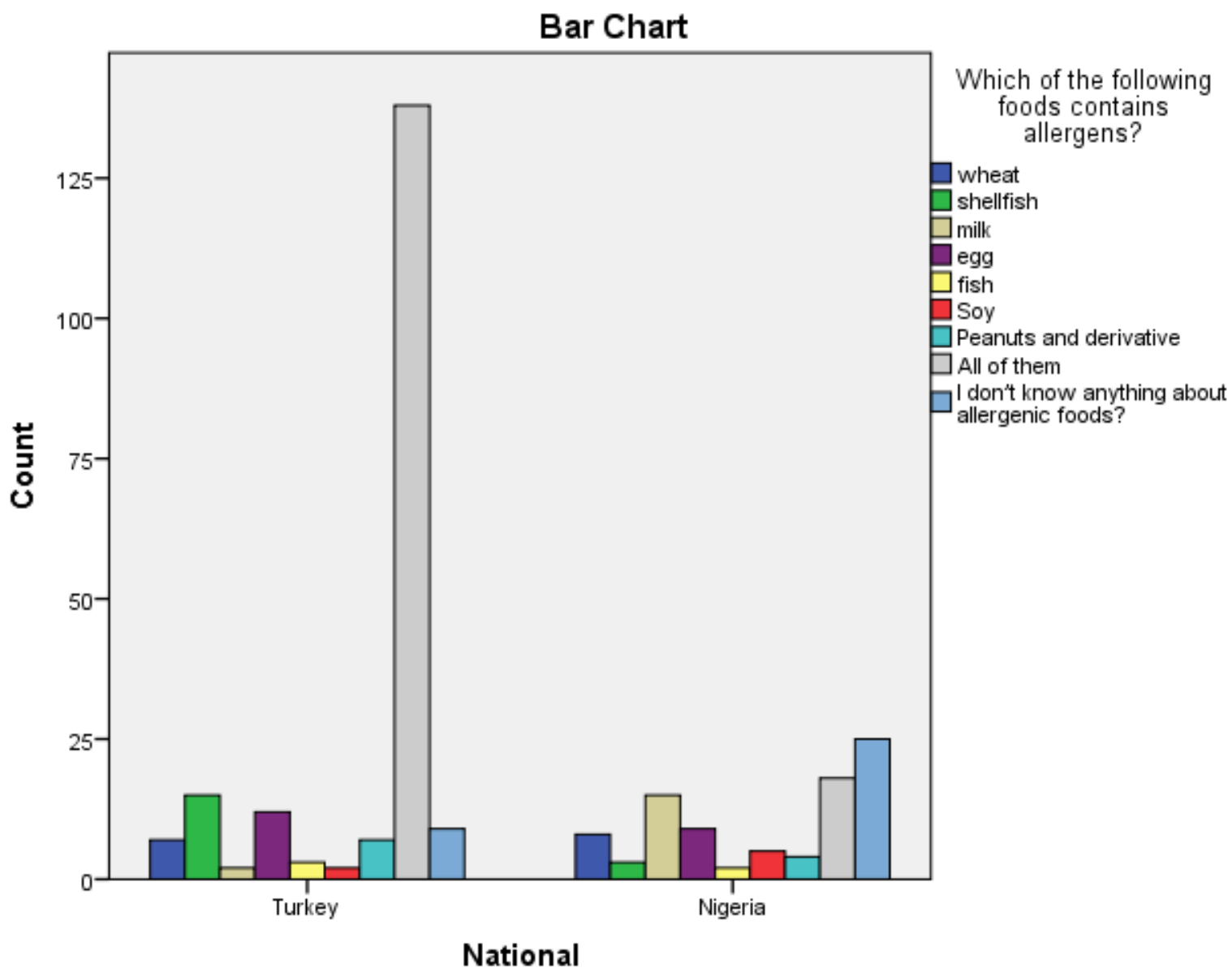

Figure 2. Knowledge of Allergens across Turkey and Nigeria.

Table 4. Have you ever come across allergen warning in the packaged foods that you are buying?

\begin{tabular}{lllll}
\hline & & Yes & No & I do not know \\
\hline \multirow{2}{*}{ Nationalty } & Turkey & $13.3 \%$ & $66.2 \%$ & $16.4 \%$ \\
\cline { 2 - 5 } & Nigeria & $32.6 \%$ & $34.8 \%$ & $32.6 \%$ \\
\hline
\end{tabular}




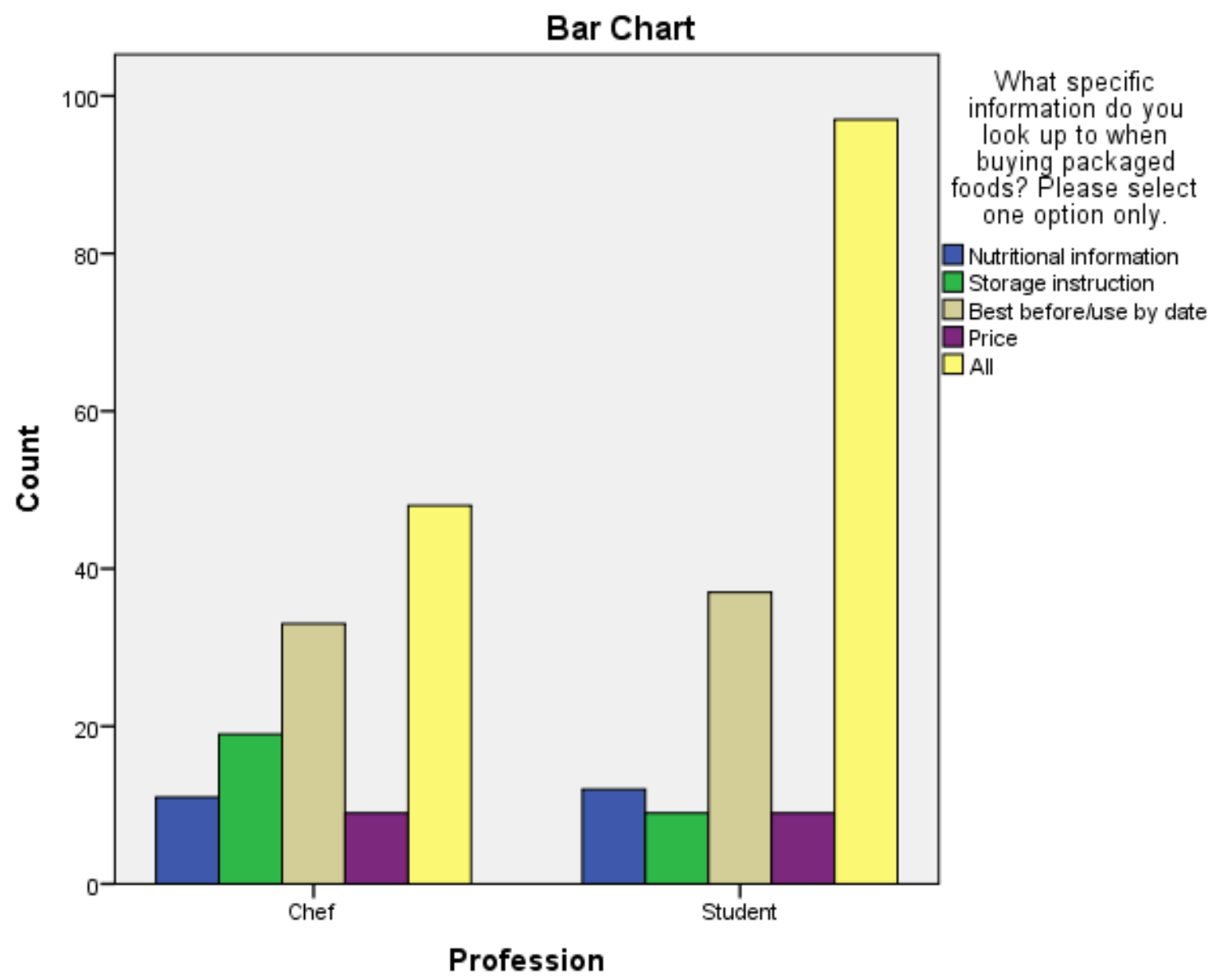

Figure 3. Information looked up when buying foods.

\section{Conclusion}

This study has examined the awareness level and attitude of chefs and students of food-related areas on food safety in general and allergens in particular. All over the world, there is an abundance of works dealing with the knowledge level of the people on food safety. What makes this study different is that the target participants are the chefs currently working in the food industry sector and the gastronomy and culinary arts students who will be qualified staff in the food sector. As a result of this study, it has been concluded that the findings of scientific studies on food safety have not been directly applied by the people working in the food sector. Additionally, another finding of this study is that the knowledge level of the gastronomy and culinary arts students on food safety and allergens are higher than the restaurant chefs that prepare foods for the public. It has been observed that there is a significant difference between the chefs and the students from both countries about allergens and food labels. In the official list of the most well-known allergens, $66.5 \%$ of the students know all of them correctly whereas only $39 \%$ of the chefs correctly identify these allergens. Moreover, $16.7 \%$ of the chefs have never heard anything about allergens which means a great problem for the consumers.

Despite this rapid development of food technology, foodrelated problems still continue. This problem can be handled by the support of the institutions offering gastronomy and culinary art through training qualified people for the sector. In addition, Government must be sure that measures to reduce food safety cases are fully applied in the food sector.

\section{Compliance with Ethical Standard}

Conflict of interests: The authors declare that for this article they have no actual, potential or perceived the conflict of interests.

Ethics committee approval: Informed consent was obtained from all participants prior to their participation in the study. 


\section{References}

Anna, M., Richard, J.M. (2007). Food Safety A Practical and Case Study Approach. New York, NY: Science and Business Media, p. 7-8, ISBN-13: 978-0387335094

Branum, AM., Susan, L., Lukacks, D.O. (2008). Food allergy among U.S. Children: trends in prevalence and hospitalizations. NCHS Data Brief, No:10, Retrieved from https://www.cdc.gov/nchs/data/databriefs/db10.pdf (accessed 10.01.2017)

Burke, T., Young, I., Papadopoulos, A. (2016). Assessing food safety knowledge and preferred information sources among 19-29 year olds. Food Control, 69, 8389.

Food Standards Agency (2007). Consumer attitudes to food standards: Wave 8 UK Report Final. Available at: http://www.foodbase.org.uk/admintools/reportdocuments/441-1-777_cas2007ukreport.pdf (accessed 06.07.2017).

Food Standards Agency (2013). Guidance on Advice on food allergen labeling Information. Available at: https://www.food.gov.uk/sites/default/files/multimedia/pdfs/publication/allergy-leaflet.pdf (accessed 28.03. 2017).

Gong, S., Wang, X., Yang, Y., Bai, L. (2016). Knowledge of food safety and handling in households: A survey of food handlers in Mainland China. Food Control, 64, 45-53.

Hassan, H. F., Dimassi, H. (2014). Food safety and handling knowledge and practices of Lebanese university students. Food Control, 40, 127-133.

Hattersley, S., Ward, R., Baka, A., Crevel, R. W. (2014). Advances in the risk management of unintended presence of allergenic foods in manufactured food products-An overview. Food and Chemical Toxicology, 67, 255-261.

Jespersen, L., Griffiths, M., Maclaurin, T., Chapman, B., Wallace, C. A. (2016). Measurement of food safety culture using survey and maturity profiling tools. Food Control, 66, 174-182.

Kabacık, M. (2013). Determınıng the food safety knowledge level of the kitchen staff working for 4 and 5 star hotel kıtchens. Ordu Üniversitesi Sosyal Bilimler Araştırmalarl Dergisi, 4(7), 112-127.

Kunadu, A. P. H., Ofosu, D. B., Aboagye, E., Tano-Debrah, K. (2016). Food safety knowledge, attitudes and selfreported practices of food handlers in institutional foodservice in Accra, Ghana. Food Control, 69, 324330 .

Kunadu, A. P. H., Ofosu, D. B., Aboagye, E., Tano-Debrah, K. (2016). Food safety knowledge, attitudes and selfreported practices of food handlers in institutional food service in Accra, Ghana. Food Control, 69, 324-330.

Lee, Y. M., Xu, H. (2015). Food allergy knowledge, attitudes, and preparedness among restaurant managerial staff. Journal of Foodservice Business Research, 18(5), 454-469.

Marshall, R. J. (Ed.). (2007). Food safety: a practical and case study approach (Vol. 1). Springer Science \& Business Media, p.38-40, ISBN- 10:0-387-33509.9

Ovca, A., Jevšnik, M., Raspor, P. (2014). Food safety awareness, knowledge and practices among students in Slovenia. Food Control, 42, 144-151.

Pratten, J., Towers, N. (2004). Food allergies and the UK catering industry: a study of the training needs for the industry to serve those with food allergies. Journal of European Industrial Training, 28(6), 490-498.

Ronald, H.S. Gary, E.R. (2002). Food Safety Handbook (p. 1-10). New Jersey, NJ: John Wiley \& Sons Inc. ISBN 0-471-21064-1

Santich, B. (2004). The study of gastronomy and its relevance to hospitality education and training. International Journal of Hospitality Management, 23(1), 1524.

Smigic, N., Djekic, I., Martins, M. L., Rocha, A., Sidiropoulou, N., Kalogianni, E. P. (2016). The level of food safety knowledge in food establishments in three European countries. Food Control, 63, 187-194.

Webb, M., Morancie, A. (2015). Food safety knowledge of foodservice workers at a university campus by education level, experience, and food safety training. Food Control, 50, 259-264. 
Woh, P. Y., Thong, K. L., Behnke, J. M., Lewis, J. W., Zain, S. N. M. (2016). Evaluation of basic knowledge on food safety and food handling practices amongst migrant food handlers in Peninsular Malaysia. Food Control, 70, 64-73.
Zhang, Y., Zhu, L., Li, S., Zhang, J., She, T., Yan, J., Li, H. (2016). Identification of the major allergenic epitopes of Eriocheir sinensis roe hemocyanin: A novel tool for food allergy diagnoses. Molecular Immunology, 74, 125-132. 